\title{
The Impact of Pre and Probiotic on Growing Performance and Haematological Parameters in Ross 708 Broiler Chickens
}

\author{
Andrei Radu SZAKACS ${ }^{1 *}$, Sorana MATEI ${ }^{1}$, Laura ŞTEFĂNUȚ ${ }^{1}$, Reka SIMCSAK ${ }^{1}$ and Adrian MACRI ${ }^{1}$ \\ ${ }^{1}$ Department of Animal Nutrition. University of Agricultural Science and Veterinary Medicine, Calea \\ Manastur, nr.3-5, 400372 Cluj-Napoca, Romania \\ *Corresponding author: andreiradu2004@yahoo.com
}

Bulletin UASVM Veterinary Medicine 72(2) / 2015,

Print ISSN 1843-5270; Electronic ISSN 1843-5378

DOI:10.15835/buasvmcn-vm: 11448

\begin{abstract}
The research was conducted on "Ross 708" broiler to evaluate the effects of dietary supplementation with prebiotics and probiotics in growth performance, feed conversion ratio and effect on some hematologic parameters. One-day old broiler chicks were divided into 4 groups: group one - fed with pro and prebiotic (synbiotic), group two - fed with prebiotic, group tree - fed with probiotic and group four - control. Control group was fed with broiler chicken commercial diet. The probiotic group was fed with the same commercial diet supplemented by BetaPro300® (Biochem), a probiotic containing Bacillus subtilis DSM 17299 in a dose of 8x10 ${ }^{8}$ colony- forming units (CFU) $/ \mathrm{kg}$. The prebiotic added for the second group contained an extract derived from cell walls of the baker yeast Saccharomyces cerevisiae (TechnoMos ${ }^{\circledR}$ - Biochem) with a dose of $0.5-1.0 \mathrm{~kg} /$ tone of feed. $700 \mathrm{~g}$ prebiotics were added in 1 tone and $300 \mathrm{~g}$ probiotics were added to each tone of commercial diet. Weight of 50 birds was measured daily. The body weight, average total weight gain and feed conversion ratio were increased by the dietary inclusion of the both pre and probiotic (2081g total body weight, $1.49 \mathrm{~kg}$ feed $/ \mathrm{kg}$ weight gain) compared with the control ( $p>0.05)$ (1875.8g, $1.71 \mathrm{~kg}$ feed $/ \mathrm{kg}$ weight gain).

The pre and probiotics increased the growth performance of broiler chickens from Ross 708 line especially when used together as symbiotic. Hematological parameters varied in physiological limits of species. In probiotic treated chickens, hematocrit, erythrocyte and leukocyte count were higher compared with the other groups ( $p>0.05$ ). Supplementation of feedstuffs with probiotics and prebiotics improved the economic efficiency of broiler growth thereby representing an important alternative for antibiotics as growth-promoting additives.
\end{abstract}

Keywords: broiler, prebiotics, probiotics, ross 708

\section{INTRODUCTION}

The poultry farming is modulated to increase the production of meat with higher efficiency of growth performance and feed conversion in a world of increasing human population and raising need for animal protein. In modern days the poultry production must take into consideration the public concerns regarding environmental and food safety. Antimicrobials are widely used to promote health and increase growing performance and feed efficiency. The stress caused by different factors including overpopulation, vaccinations, environmental conditions may weaken the resistance of broiler chicken to different pathogens. The use of antibiotics is widespread in the world in order to prevent or treat pathological conditions in bird flocks. We must point out certain concerns regarding their relatedness with similar substances used in humans due to the possibility of appearance of drug resistant bacteria in humans (Philips, 1999). 
In the United States, it was reported that antimicrobials are included in $90 \%$ of starter diets, $75 \%$ of grower diets, and more than $50 \%$ of finishing diets (NRC, 1999).

Hays (1978) found a response of chicken to antibiotics with an improvement of $15.98 \%$ in daily gain and $9.06 \%$ improvement in feed efficiency.

Antibiotic growth promoters are under investigation for many years and some countries have implemented strictguidelines and regulations on the use of these drugs for production purposes in some areas being removed from the market (Ratcliff, 2000)

Therefore the study of alternative ways of animal disease prevention by the use of pro and prebiotics has gained a momentum (Awad et al., 2009).

Probiotics are defined as living microorganisms which administered to animals stimulates the colonization of the intestine with certain bacteria which is beneficial to animal and antagonistic to other pathological microbes (Green and Sainsbury, 2001).

Prebiotics are non-digestible feed ingredients ( $\beta$-(1.3)-Glucans and Mannanoligosaccharids) which stimulate, according a selective way, on the colon level, the multiplication or the activity, of one or a limited number of bacteria groups, able to improve the physiology of the host.

\section{MATERIALS AND METHODS}

Investigations were performed in a broiler chicken farm from Bihor County and in Department of Nutrition and Physiology of Veterinary Medicine Faculty Cluj-Napoca. The study was conducted between 15 May and 29 June 2015 on broiler from Ross 708 line. The animals were grouped in 4 compartments of 26,500 broilers each. The experimental groups were housed in 2 shelters with 4 separated areas with a total of $3373.65 \mathrm{~m}^{2}$.

Two commercial products produced by Biochem company (Germany) were used - a probiotic (BetaPro ${ }^{\circledR}$ 300) and a prebiotic (TechnoMos®). TechnoMos® is an extract of cell wall of yeasts (Saccharomyces cerevisiae) with an optimum composition in $\beta$-(1.3)-Glucans (30 $\%)$ Mannanoligosaccharids (MOS) (30\%) and proteins (12.5\%). $\beta$-(1.3)-Glucans have a proven stimulating effect on nonspecific immunity of broilers which is important for young animals or in stressful situations (grouping, transportation, feedstuff change, vaccinations). Because of the specific affinity certain microorganisms are connected to these substances. The complex MOS Escherichia coli, Salmonella spp., Clostridium spp. is consecutively eliminated through feces (Yang et al., 2009). The prebiotic is administered in an amount of $700 \mathrm{~g} /$ tone of feedstuff. BetaPro® 300 is an additive composed of Galli Pro® and Betaine and contains 2,7 x $10^{9} \mathrm{CFU} / \mathrm{g}$ Bacillus subtilis and $778 \mathrm{mg} / \mathrm{g}$ de Betaine. Used in feedstuffs of broilers it enhances productive parameters preventing diarrhea and stabilizing the microflora from the gut. BetaPro ${ }^{\circledR} 300$ was administered in investigated group in dose of $300 \mathrm{~g} /$ tone of final feedstuff.

Products were administered as follows: group 1 - pro- and prebiotic associated (synbiotic), group 2 - prebiotic, group 3 - probiotic and group 4 - control untreated. Control group received a specific feedstuff used for different age category, for the other groups being added specified substances. Pro and prebiotics were present in feeds from 0 to 34 days of age. A total number of 200 animals were weighted every day, an equal number from each group. Feed consumption was noted separately for each group and each kind of feed. Chicks were fed at the age of 0 days through day 10 with the prestarter feed, from day 11 to 24 days the starter feed, from day 25 to 30 days feed for growth period and from day 30 to the slaughter with finishing feed.

In order to calculate the amount of feedstuff consumed by the one broiler the following formula was used:

Consumed feedstuff/broiler chicken $(\mathrm{g})=$ $\frac{\text { total consumed feedstuff }(\mathrm{kg})}{\text { total number of broilers - number of dead chickens }} \times 1000$ $\frac{\text { total consumed feedstuff }(\mathrm{kg})}{\text { total number of broilers - number of dead chickens }} \times 1000$

The body weight incresase for the entire period was calculated using the formula:

Increase in body weight $=$ weight at day $36-$ weight at day 0 .

Similar way was used to calculated the increase in body weight for all feeding periods: prestarter period, starter period, grower period and finishing period.

Blood samples were collected from 5 chickens from each group in day 33 of experiment for hematology analyze. Hematology investigations 
consist in hematocrit, total hemoglobin, total erythrocytes and total leucocytes and meant to assess the health state of investigated animals.

Statistical data interpretation was made using Dunnett Multiple Comparisons Test (Anova system) in the computer software GraphPad InStat.

\section{RESULTS AND DISSCUSION}

Data on live weight gain, mortality, quantity of consumed feedstuff per period or per total, growing rate are presented in Tab. 1 and Fig. 1,2 and 3 . The results obtained in measuring the weight indicates a variation of growth performance in total period with a much higher value in the compartment treated with synbiotic compared with rest of groups ( $\mathrm{p}>0.05)$. Regarding the comparative analyze of weight evolution it was measured that the broiler treated with probiotic had a lower value compared with the synbiotic group and the probiotic and the control presented similar evolutions. By the age 20 days chicken from the probiotic treated compartment had a higher weight than control but after these day the situation got and staid reversed till the end of investigation. At day 36 the control group had more with 50 grams compared with the probiotic group.

In the prestarter period the groups treated with prebiotic and probiotic presented an increased weight growing rate compared with the control group. In this period the synbiotic treated group exhibited higher weight gain (Fig.1). The starter period presented an interesting change in weight gain speed of investigated groups -the prebiotic compartment overtakes the synbiotic treated group. The other two groups have similar evolutions. In the growing period the control group had almost 30 grams higher weight gain compared with the probiotic group. The first place in this period is taken by synbiotic treated group, followed by the prebiotic group. The finishing period shows a regress of probiotic and prebiotic in gain speed compared with control group where synbiotic group maintains the leader position.

The analysis of data evidenced that the average live weight gain was found higher $(\mathrm{p}>0.05)$ in preand probiotic broilers as compared to control birds when total period is considered. This result is correlated with the actual published research

Tab.1. Investigated groups structure, mortality and total consumed feedstuff/group

\begin{tabular}{|c|c|c|c|c|c|}
\hline Period & Parameters & $\begin{array}{l}\text { Synbiotic } \\
\text { group (1) }\end{array}$ & $\begin{array}{l}\text { Prebiotic } \\
\text { group (2) }\end{array}$ & $\begin{array}{l}\text { Probiotic } \\
\text { group (3) }\end{array}$ & $\begin{array}{c}\text { Control } \\
\text { group (4) }\end{array}$ \\
\hline \multirow{3}{*}{ Prestarter } & $\begin{array}{l}\text { Total number of } \\
\text { chicken/group }\end{array}$ & 26000 & 27139 & 27000 & 26000 \\
\hline & Mortality (nr.) & 258 & 263 & 171 & 140 \\
\hline & $\begin{array}{l}\text { Total consumed } \\
\text { feedstuff }(\mathrm{kg})\end{array}$ & 7960 & 7960 & 8100 & 8000 \\
\hline \multirow{3}{*}{ Starter } & $\begin{array}{l}\text { Total number of } \\
\text { chicken/group }\end{array}$ & 25742 & 26876 & 26829 & 25860 \\
\hline & Mortality (nr.) & 246 & 261 & 283 & 231 \\
\hline & $\begin{array}{l}\text { Total consumed } \\
\text { feedstuff }(\mathrm{kg})\end{array}$ & 39020 & 39700 & 40020 & 40120 \\
\hline \multirow{3}{*}{ Growing } & $\begin{array}{l}\text { Total number of } \\
\text { chicken/group }\end{array}$ & 25496 & 26615 & 26546 & 25629 \\
\hline & Mortality (nr.) & 52 & 45 & 87 & 98 \\
\hline & $\begin{array}{l}\text { Total consumed } \\
\text { feedstuff }(\mathrm{kg})\end{array}$ & 24040 & 23920 & 24080 & 24760 \\
\hline \multirow{3}{*}{ Finishing } & $\begin{array}{l}\text { Total number of } \\
\text { chicken/group }\end{array}$ & 25444 & 26570 & 26459 & 25531 \\
\hline & Mortality (nr.) & 43 & 39 & 60 & 63 \\
\hline & $\begin{array}{l}\text { Total consumed } \\
\text { feedstuff }(\mathrm{kg})\end{array}$ & 9420 & 9520 & 7940 & 8220 \\
\hline
\end{tabular}




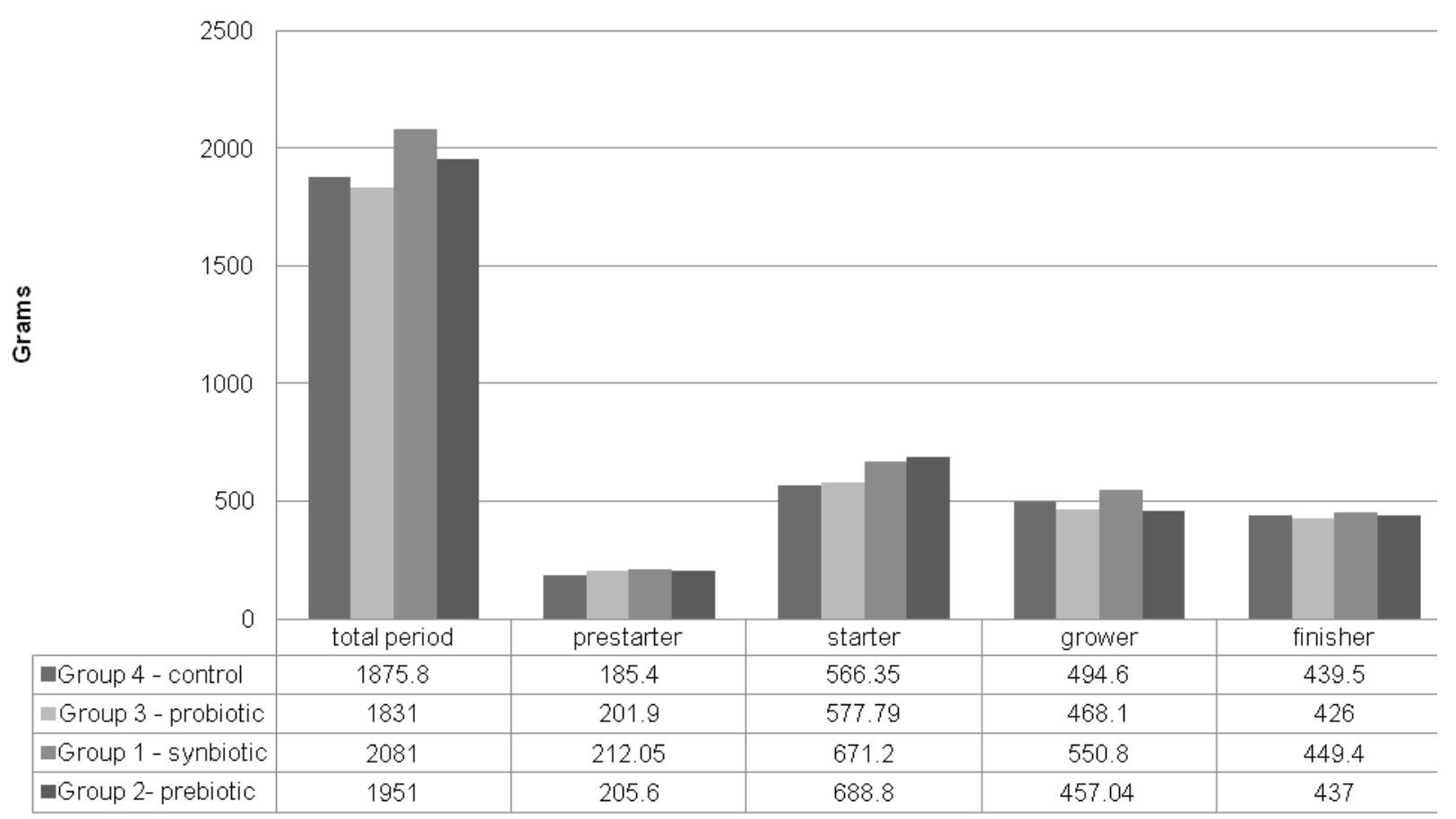

Fig. 1. Growing rate of each category of broiler in different groups

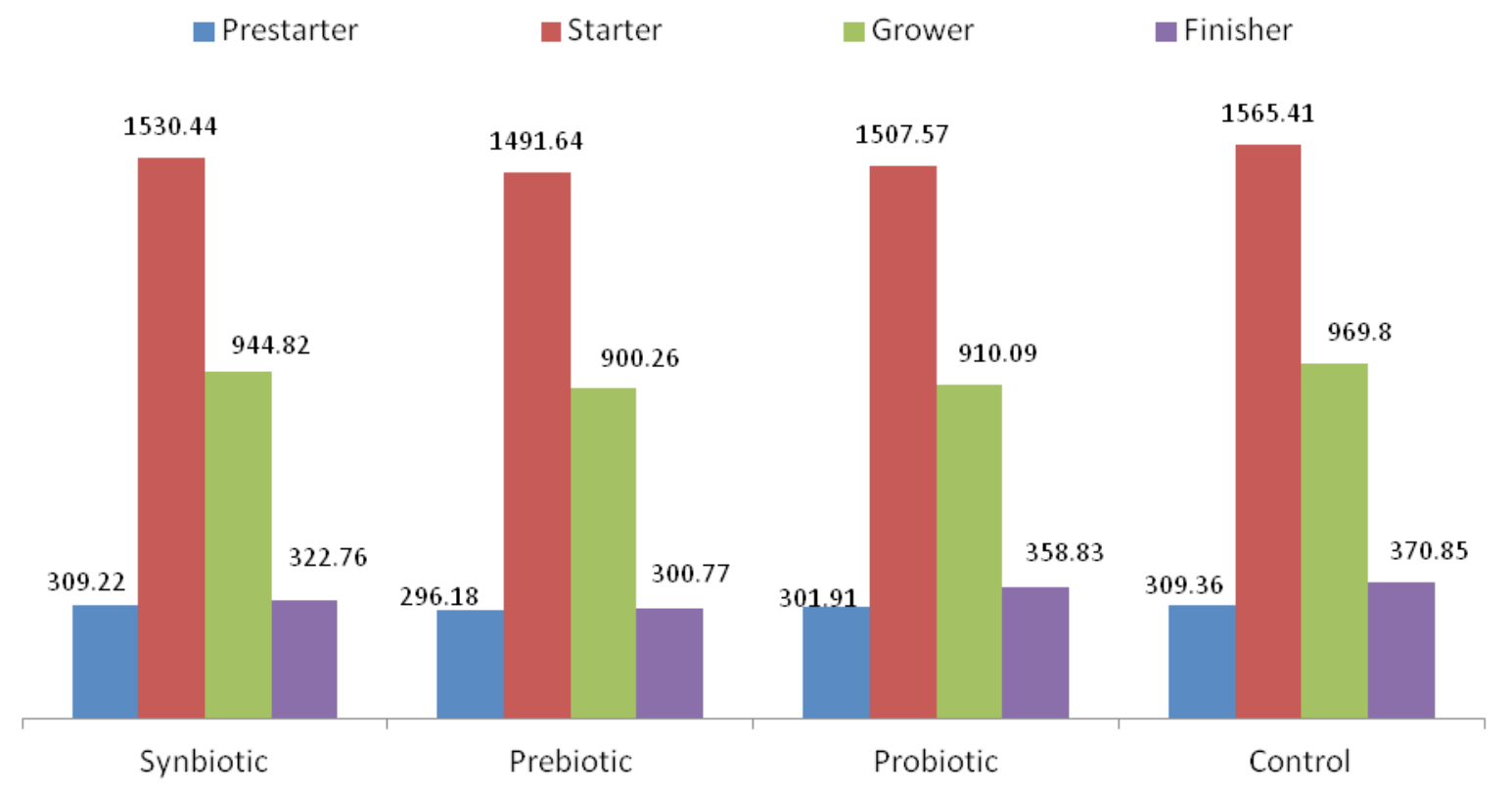

Fig.2. Feedstuff consumption / broiler depending on feeding stage

where increased live weight gain in probiotic fed birds was demonstrated (Manickam, 1994; Gunes, 2001; Cortes, 2000; Hamid, 2001; Shoeib, 2002).

The feedstuff consumption varied between investigated groups (Fig.3.). The control group had the highest amount per broiler, while the prebiotic treated group had the lowest value. This data do not correlate with the final body weight mean where situation is reversed.

Intestinal microorganisms have important effect upon nutrition, health and weight gain performance of broiler chicken, interacting with the nutrients and affecting the gut development. In case of pathologic bacteria in intestine the 


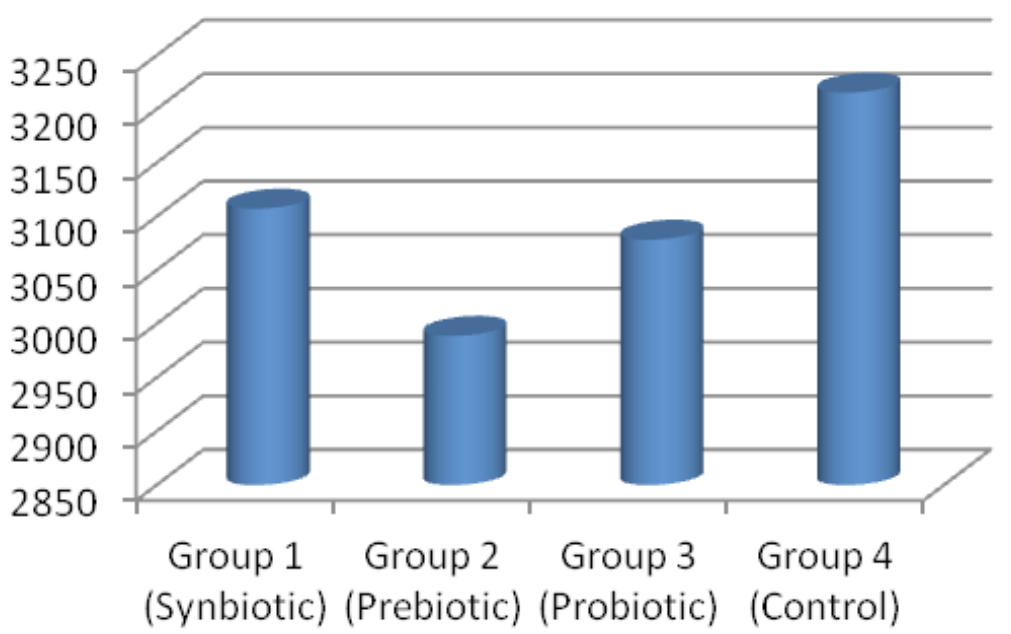

Fig. 3. Total feedstuff consumtion (g)/ broiler/total period

Tab.2. The mean values of haematological parameters

\begin{tabular}{ccccc}
\hline \multirow{2}{*}{ Analyzed parameters } & \multicolumn{4}{c}{ Experimental groups } \\
\cline { 2 - 5 } & Group 4 & Group 3 & Group 1 & Group 2 \\
\hline hematocrit (\%) & $30.20 \pm 4.15$ & $41.20 \pm 5.59$ & $31.20 \pm 3.19$ & $22.00 \pm 2.55$ \\
\hline red blood cell (T/L) & $2.50 \pm 0.35$ & $3.06 \pm 0.53$ & $2.66 \pm 0.30$ & $2.68 \pm 0.30$ \\
\hline hemoglobin (g/dl) & $15.52 \pm 0.47$ & $16.96 \pm 1.02$ & $17.31 \pm 1.27$ & $17.38 \pm 0.99$ \\
\hline white blood cells (G/L) & $20.50 \pm 3.85$ & $31.60 \pm 8.14$ & $14.80 \pm 9.08$ & $18.00 \pm 4.43$ \\
\hline
\end{tabular}

integrity and vital functions are strongly affected and the immunity is overstimulated. When birds are grown in an environment free of bacteria and viruses determine an increase in live weight gain of $15 \%$ (Yang, 2009).

Administering pro- and prebiotics in feedstuff has beneficial effect on immunity as well as on weight gain. Patterson (1997) shows that the administration of fructooligosaccharides increased the number of bifido-bacteria 24 times and of lactobacilli of 7 times compared to control. The author observed an increase in body weight gain and reduced mortality. In comparison our investigation shows higher mortality in probiotic and prebiotic group than control in the first two stages whereas in the grower and finisher period was lower even by half.

The analysis of the hematological results reveals different aspects depending on the parameters investigated and experimental group. The hematological parameters were between physiological limits of species and age. No significant differences were observed compared to control group ( $\mathrm{p}>0.05)$. Distinct situations were found in case of probiotic-treated chickens, in this group the values of the hematocrit and total erythrocytes were higher compared to the other groups. The same situation was observed in case of the total number of leukocytes. Generally, the administration of probiotics induce the immunostimulation by different mechanisms, one of the most important is the production of cytokines which are involved in the control of leucopoiesis.

\section{CONCLUSION}

From the present results it was concluded that supplementation of probiotics and prebiotics had stimulatory effects on broiler growth performance in broilers. The mixture of pre- and probiotic had the highest impact on growth of broiler chicken from line Ross 708.

\section{REFERENCES}

1. Awad WA, Chareeb K, Abdel-Raheem S, Bohm J (2009). Effects of dietary inclusion of probiotic and symbiotic 
on growth performance, organ weight and intestinal histomorphology of broiler chickens. Poult Sci 88:49-56.

2. Cortes CA, Avila GE, Casaubon HMT, Carillo DS (2000). The effect of Bacillus toyoi on broiler performance. Veterinaria Mexico 31:301-308.

3. Green A A, Sainsbury D W B (2001). The role of probiotic in producing quality poultry products. XV European Symposium on the quality of poultry meat. Kusadasi, Turkey, 9-12 September, 245-251.

4. Gunes H, Altinel A, Cerit H (2001). Effect of preprobiotic (fermacto-500) on the yield characteristics of broiler chickens. Veteriner Fakultesi Dergisi Istanbul 27:217-228.

5. Hamid MS, Qureshi A (2001). Trial study on the efficacy of protexin (water-soluble) on the performance of broilers. Pak Vet J 21:224-225.

6. Hays VW (1978). Effectiveness of Feed Additive Usage of Antibacterial Agents in Swine and Poultry Production. Report to the Office of Technology Assessment. US Government Printing Office, Washington DC.

7. Manickam R, Viswanathan K, Mohan M (1994). Effect of probiotics in broiler performance. Ind Vet J 71:737-739.
8. Paterson O, Richards S (1997). Selective enrichment of Bifidobacteria in the intestinal tract of broilers by thermally produced ketoses and effect on broiler performance. Poultry Science, London, 1351-1356.

9. Philips I (1999). Assessing the evidence that antibiotis growth promoters influence human infections. J Hospital Infections 43:173-178.

10. Ratcliff J (2000). Antibiotic bans-a European perspective. In : Proceeding of the $47^{\text {th }}$ Maryland Nutrition Conference for Food Manufacturers, March 22-24, 135-152.

11. Shoeib H K, Madian A H (2002). A study on the effect of feeding diets containing probiotics (Pronifer andbiogen) on growth performance, intestinal flora and haematological picture of broiler chicks. Assiut Vet Med J 47:112-125.

12. USA National Research Council (1999). Use of Drugs in Food Animals: Benefits and Risks. National Academy Press, Washington, DC.

13. Yang Iji Choct (2009). Dietary modulation of gut microflora in broiler chickens: a review of the role of six kinds of alternatives to in-feed antibiotics. World's Poultry Science Journal 65:97-98. 